\title{
Effect of entomopathogenic nematodes under laboratory conditions on Cylas puncticollis pest of sweet potato in Benin
}

\author{
André Antoine FANOU ${ }^{1 *}$, Hugues BAIMEY ${ }^{1}$ and Audrey TOTIN ${ }^{2}$ \\ ${ }^{I}$ Faculty of Agronomy, University of Parakou PO BOX 123 Parakou Republic of Benin. \\ ${ }^{2}$ African University of Technology and Management, PO BOX 04 BP 1361 Cotonou Republic of Benin. \\ "Corresponding author; E-mail: andrefanou@gmail.com; Tel: 22997601836
}

\begin{abstract}
Sweet potato is an economic crop. Unfortunately, it is greatly affected by Cylas puncticollis. To control this pest, farmers use insecticides. Today, find a biological control method against this pest is necessary. Thus, the pathogenicity of ten isolates of entomopathogenic nematodes Heterorhabditis has been tested under laboratory conditions using three local varieties of sweet potato. Ten sliced sweet potato of each variety have been placed in Petri dishes and have been infested with 3 males and 7 females of Cylas puncticollis. After two weeks, the rings have been inoculated with 20 or 40 nematodes and Petri dishes were arranged in a completely randomized design. Washers that received no inoculum of nematodes and insects and those fed only insects were the control treatments. Analysis of variances using the SAS programme showed that the effect of weevils on tuber slice's quality is significantly higher compared with its effect on the amount of tuber. All isolates of nematodes used were effective and significantly reduced the emergence of adult insects. Moreover, these entomopathogenic nematodes were more effective on weevil larvae than other development stages. The isolates $63 \mathrm{c}, 62 \mathrm{~b}$ and $5 \mathrm{~d}$ have distinguished themselves by their effectiveness. In addition, all isolates of nematodes have the potential to multiply and thus to persist.
\end{abstract}

(C) 2019 International Formulae Group. All rights reserved.

Keywords: Biological control, Ipomoea batatas, Cylas puncticollis, Heterorhabditis, pathogenicity.

\section{INTRODUCTION}

Originally from America, sweet potato (Ipomoea batatas Lam.) is a plant with tuberous roots that has great economic importance in the tropics, mild subtropical and temperate regions (Sivparsad and Gubba, 2012). This is the seventh most important crop in the world after wheat, rice, corn, potatoes, barley, and cassava and third in Benin after cassava and yam among the roots and tubers. Its worldwide production is estimated at 124 Mt in 2007, of which over $88 \%$ in Asia particularly in China with 100Mt (FAOSTAT,
2008). The tuberous roots contain large amounts of starch that can reach $30 \%$ of the fresh weight in some cultivars. Sweet potato can produce more edible energy per hectare per year as wheat, rice and cassava (Pathleen and Janet, 2015). The roots are used for human food, alcohol production and animal nutrition. The stems and leaves are used as fodder (Glato et al., 2014).

Several factors limit the production of sweet potato, including the lack of healthy crops or improved materials, poor farming practices, drought, diseases and pests 
(Dossou-Aminon et al., 2014). The main insect pest that harms sweet potato production is weevil Cylas spp (Ebregt et al., 2007; Andrade et al., 2009). The most important species are Cylas brunneus, (Olivier) Cylas puncticollis (Fabricius) and Cylas formicarius (Fabricius) (Coleoptera: Apionidae). The two common species $C$. brunneus and $C$. puncticollis are the largest in East Africa and are widespread in all the sweet potato growing areas (Echodu et al., 2018).

The damage caused by the weevil sweet potato drives the low yields, poor quality root for consumption (Azerad, 2000) and infected plants. The poor quality of roots also creates marketing problems (CIP, 2007). Studies have reported yield losses ranging from $5 \%$ to $100 \%$ in areas where weevil infestation is widespread (Hashim et al., 2017). Surveys conducted in Kenya and Uganda on C. brunneus and C. puncticollis indicated that they may affect the harvest throughout the year (Ebregt et al., 2005). According to Maling'a (2000); Weevils are more abundant and harmful in the dry season. The cracks formed during the drought make them more accessible to root weevil infestations (Stathers et al.,, 2003).

Most of the sweet potato producers store earth roots and carry out harvesting disparately (Ebregt et al., 2004). Several times during the growing season, farmers remove large roots to maturity without uprooting the plant itself, but the sweet potato roots are extremely vulnerable to weevils if left unharvested. CIP (2008) observed that a fragmentary harvest reduced the infestation of weevils but yields are low for the next harvest. Symptoms of weevil infestation of sweet potato vines are yellowing, tunnels inside the rods that extend inward causing blackening and cracking vineyards or their collapse. Infested roots shave along the twisted tunnels, filled with excrement are often spongy appearance. The roots also develop secondary infections such as root rot (dark) and changes in quality of terpenes (Azerad, 2000) and flavor.
The sweet potato (Ipomoea batatas L. Lam) is widely cultivated around the world primarily for its edible roots (Ukom et al., 2009) high in calories; dietary fiber and certain biologically active phytochemicals such as beta-carotene, polyphenols and ascorbic acid (Ahmed et al., 2010). The sweet potato is one of the most effective food crops in terms of caloric value per acreage. It has many agronomic benefits to marginal lands (including drought tolerance) and is relatively easy to grow even in poor soils (Van oirschot et al., 2003); unfortunately it remains underexploited among the main crops in developing countries (Tomlins et al., 2012) and is attacked by the insect Cylas spp creating galleries in the potato, that significantly reduce its marketability. It appears important, even crucial, to seek all necessary means that can help to fight effectively against these pests. Thus, many ways to struggle against this pest have been developed. Among them, chemical control is the oldest and most widely used to control the population of this insect. Its application had early in his development spectacular success, but a gradual decrease in its efficiency rating over time. This is due to the adaptation system, development of resistance toward pesticides pests (Crinnion, 2009).

To achieve a significant reduction in the population of the pest due to resistance development problem, farmers use many insecticides more toxic and increase the number of pesticide applications while regularly changing (Dufumier, 2005). But if the repeated application of highly toxic pesticides may reduce populations of pests, it is far from environmentally and socially sound and is done at great expense. Also, these products are responsible for several cases of poisoning and according to UN estimates, each year, 40,000 victims and cause squealed in approximately 2.000000 people (IITA, 1988). The main objective of this work was to find out an effective way for a significant reduction in the use of synthetic insecticides in favor of biological control. 


\section{MATERIALS AND METHODS \\ Experimental site}

The work was conducted in the laboratory of the Nematology Section at the International Institute of Tropical Agriculture (IITA), Benin station.

\section{Sweet potato varieties}

Three sweet potato varieties grown in southern Benin were used. They were selected and purchased in a local market. Roots of these three varieties of sweet potato showed no signs of Cylas spp infestation.

The first variety, locally called Glassodji has a red skin and white flesh; the second named Gboado has a yellow skin and pale yellow flesh; while the third one called Bohounbo shows a purple skin and yellow flesh ( Figure 1).

\section{Multiplication of Cylas puncticollis}

The multiplication is performed in plastic boxes containing potato roots that were inoculated with a population of three males and seven females of $C$. puncticollis (Houékpétodji, 2018). The boxes were then closed with screen covers and kept under laboratory conditions. The insects breed by laying eggs in the tunnels that they dig in the roots.

\section{Entomopathogenic multiplication}

The multiplication of entomopathogenic nematodes has followed two steps: larval mass production of Galleria mellonella and then the inoculation of the larvae with entomopathogenic nematode isolate followed by the White Trap technique.

To multiply Galleria mellonella, bees wax sample obtained previously and containing insect larvae was placed in a plastic bowl $5000 \mathrm{cc}$ volume having a perforated cover to facilitate ventilation. After a complete metamorphosis, the larvae become adults. The adult insects (male and female) were transferred to a new transparent bowl of the same volume containing wax previously dried in the sun for producing new larvae. The new larvae were inoculated with pure isolates of entomopathogenic nematodes. The killed larvae were put in White Trap dispositive to enable entomopathogenic nematodes' multiplication and their emergence. The multiplied isolates for conducting the trials are presented in Table 1.

\section{Trials installation}

\section{Preparation of Petri dishes}

Petri dishes of $9 \mathrm{~cm}$ in diameter were used in the installation of the trials. They have been carefully soaked in bleach and washed with a sponge and MIR liquid soap. They were then rinsed with clean water twice and exposed to the sun for drying. The lids were then pierced to allow for ventilation in the boxes and avoid the death by suffocation of the insects. In total, 68 Petri dishes were used.

The cover of each petri dish was labelled according to the different treatments studied as followed:

Different treatments studied for each insect stage

Two treatments were selected and repeated three times, they are:

Treatment 1: + Cylas + nematodes: for Cylas boxes containing insects and nematodes,

Treatment 2: + Cylas - nematodes: nematodes for the boxes containing insects Cylas but not containing nematodes, TT, (control treatment).

\section{Preparation of sweet potato slices}

Roots were rinsed with water, dipped in a fungicide solution of TOPSIN-M (Thiophanate-Methyl that is a registered trademark of Nippon Soda Company, Ltd) for 30 minutes at the concentration of $50 \mathrm{~g}$ of fungicide for 5 liter of water. The roots were removed from the solution and exposed to sunlight for 5 to 10 minutes.

The tubers were then cut into slices 10 $\mathrm{g}$ each with a knife disinfected with alcohol. A precision scale was used for weighing. They were then exposed to sunlight for 5 to 10 minutes to allow healing.

Potato slices were introduced in Petri dishes, and then 10 insects (Cylas punticollis), seven females and three males were put in 
each Petri dish. The dishes were closed with their lids labelled, and stored on a shelf in a completely randomized design.

\section{Inoculation of Cylas-infested slices with nematodes}

Inoculation of sweet potato slices with nematodes was done 15 days after the introduction of an adult of $C$. puncticollis on sweet potato root washers. During that period, the tubers attached washers contained larvae of the insect and had a ragged appearance. Two initial nematode densities of the population were used for each isolate of nematode (20 and 40 nematodes / sweet potato roots washer). In each case, the nematodes were collected from mother's suspensions using a micropipette $1000 \mu \mathrm{l}$ capacity and a manual counter. After each inoculation, tips of the micropipette was replaced to avoid a mixture of inoculum. The Petri dishes were closed with their lids and then ranged in rows in a completely randomized block, and each treatment was repeated three times. Washers representing the flat treatment TT have received or nematodes or insects. Three sweet potato slices were also used for each of these control treatments.

\section{Collecting of data}

Five days after inoculation with the entomopathogenic nematodes, the following data has been collected:

Loss in mass of sweet potato, number of dead larvae, number of dead pupae, number of dead adult insects, and nematode reproduction index was calculated.

\section{Loss in mass of sweet potato}

The loss in mass of sweet potato has been collected by recovered and stripped the roots of live and dead larvae and pupae before being weighed with a precision balance 21 days after installation and testing 05 days after inoculation with the insect pathogenic nematodes.

\section{Number of dead larvae, pupae and adults}

The number of dead larvae, dead pupae and dead adults has been registered by collected carefully with the pliers and counted by isolates of nematodes in Petri dishes. Then the numbers determined after counting were subjected to analysis of variance.

\section{Nematode reproduction index}

Nematodes that emerged from the White device were then counted as follows: $10 \mathrm{ml}$ were poured into a test tube and supplemented with water up to $40 \mathrm{ml}$. Then with a pipette $3 \mathrm{ml}$ were collected and poured into a counting box and worn under a microscope to count with a manual counter. The breeding index was calculated using the following formula: final nematode population density / initial density nematode population.

\section{Statistical analysis}

The Analysis of Variance (ANOVA) of collected data was done using Generalized Linear Model (GLM) of the Statistical Analysis System (SAS) version 9.1. to determine the significant difference at 0.05 level.

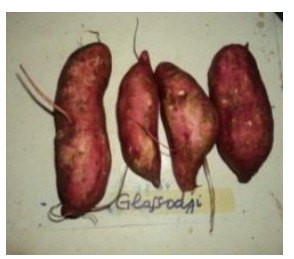

Glassodji

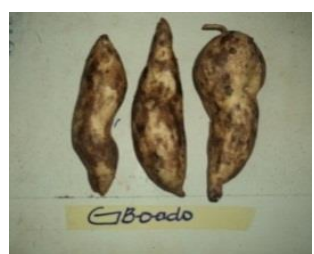

Gboado

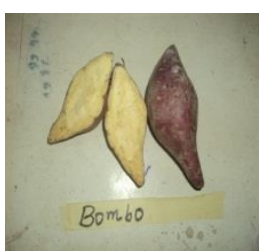

Bohounbo

Figure 1: Different varieties of sweet potato used during the experiment 
Table 1: Isolates of nematodes used in the experiment.

\begin{tabular}{lllll}
\cline { 3 - 3 } & \multicolumn{3}{c}{ Origin } \\
\hline Isolate & Village & Commune & Department & Vegetation \\
\hline $5 \mathrm{~d}$ & Adja Ouere centre & Adja Ouere & Plateau & Orange \\
$9 \mathrm{~d}$ & Hessa & Adjohoun & Oueme & Oil Palm tree \\
$32 \mathrm{~b}$ & Azongo Azohoue & Tori Bossito & Atlantique & Orange \\
$44 \mathrm{a}$ & Kemondji & Zakpota & Zou & Orange \\
$62 \mathrm{~b}$ & Djidja & Djidja & Zou & Neem \\
$63 \mathrm{c}$ & Kassehlo & Djidja & Zou & Nere tree \\
$64 \mathrm{~b}$ & Dan & Djidja & Zou & Orange \\
$80 \mathrm{a}$ & Awokpa & Zè & Atlantique & Banana \\
$83 \mathrm{a}$ & Zè centre & Zè & Atlantique & Oil palm tree \\
$111 \mathrm{c}$ & Okoutaossé & Bantè & Colline & Baobab
\end{tabular}

\section{RESULTS}

\section{Loss in mass of sweet potato varieties}

After the inoculation of the slices with C. puncticollis, those slices have been attacked and completely damaged by the insects as shown by Figure 2.

Variance analysis focusing on the loss in potato mass revealed a difference between the treatments at the $5 \%$ probability for varieties Bombo, Gboado and Glassodji. Roots infected with $C$. puncticollis but that have not been submitted to nematodes (TT) recorded the most weight loss (Figure 3). There is no difference between the treatments that received nematodes; (Table 2). The variety that had the least loss is the variety Bohounbo monitoring Glassodji and Gboado (Table 2) (Figure 3).

\section{Average number of dead larvae}

The analysis of variance showed a significant $(P=0.02)$ difference between treatments for Bohounbo variety (Table 3). The average number of the highest dead larvae was obtained with the isolate $63 \mathrm{c}$ with an average of 21 dead larvae regardless of nematode dose used (Figure 4).

With the variety Gboado, it was found a difference $(P=0.02)$ among treatments with the dose of 20 nematodes, which was not the case at the dose of 40 nematodes (Table 3). The highest average number of the dead larvae is 4 and it has been obtained with the isolate 44a (Figure 5).

The analysis of variance carried out on the variety Glassodji showed the existence of a significant $(P=0.01)$ difference between treatments (Table 3). This difference was more significant at a dose of 40 nematodes with an average of 5 dead larvae obtained with the isolate 111c (Figure 6).

\section{Average number of dead pupae}

The analyses of variance on the average number of dead pupae revealed a significant $(P=0.04)$ difference between treatments for the variety Bohounbo with the dose of 20 nematodes (Table 4). The highest average number is 2 dead pupae recorded with the isolate $64 \mathrm{~b}$ (Figure 7). With the dose of 40 nematodes, no difference has been found.

Concerning the variety Gboado, the analysis indicated that whatever the nematode dose (20 and 40) used, a significant $(P=0.01$ and 0.03 ) difference among treatments has been obtained (Table 4). The highest numbers of dead pupae were recorded with isolates $32 b$ 
and $5 \mathrm{~d}$ with 2 and 3 dead pupae respectively with 20 and 40 nematodes (Figure 8).

As far as the variety Glassodji is concerned, no significant difference has been observed regardless of the nematode dose used (Table 4). The highest number of dead pupae was recorded with nematode isolates 63c, 9d and 111c (Figure 9).

\section{Average number of dead adult insects}

Dead insects have been collected and counted by nematode isolate before being subjected to analysis. The analysis of variance carried out on the average number of dead insects did not show any significant difference $(\mathrm{P}=0.9)$ with the dose 20 nematodes but showed significant difference $(P=0.007)$ with the dose 40 nematodes for the variety Bohounbo (Table 5).

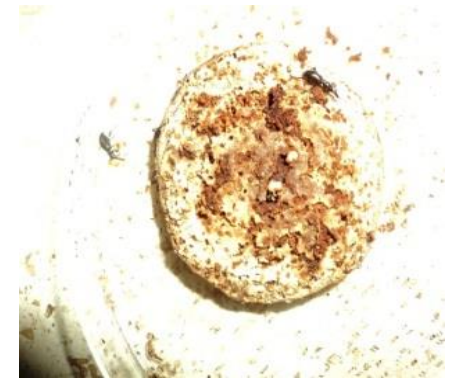

Regarding varieties Gboado and Glassodji no significant difference has been found regardless of the dose of nematodes used (Table 5).

\section{Average rate of multiplication of different isolates of nematodes}

The nematode' isolates after penetrating the insects and killing them multiply inside the insects. Figure 10 presents the behavior of ten isolates of nematodes used depending on the applied density. It appears that all isolates used have increased in number and therefore have reproduced. It was also found that the density of 20 nematodes have increased much more than the density of 40 nematodes (Figure 11). The isolates of nematode that have the highest multiplication rate were $80 \mathrm{a}, 64 \mathrm{~b}$ and $62 \mathrm{~b}$ (Figure 10 ).

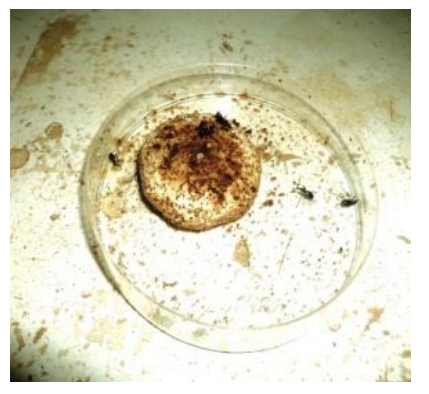

Figure 2: Appearance of sweet potato slices after 15 days (just before inoculating sweet potato slices with entomopathogenic nematodes.

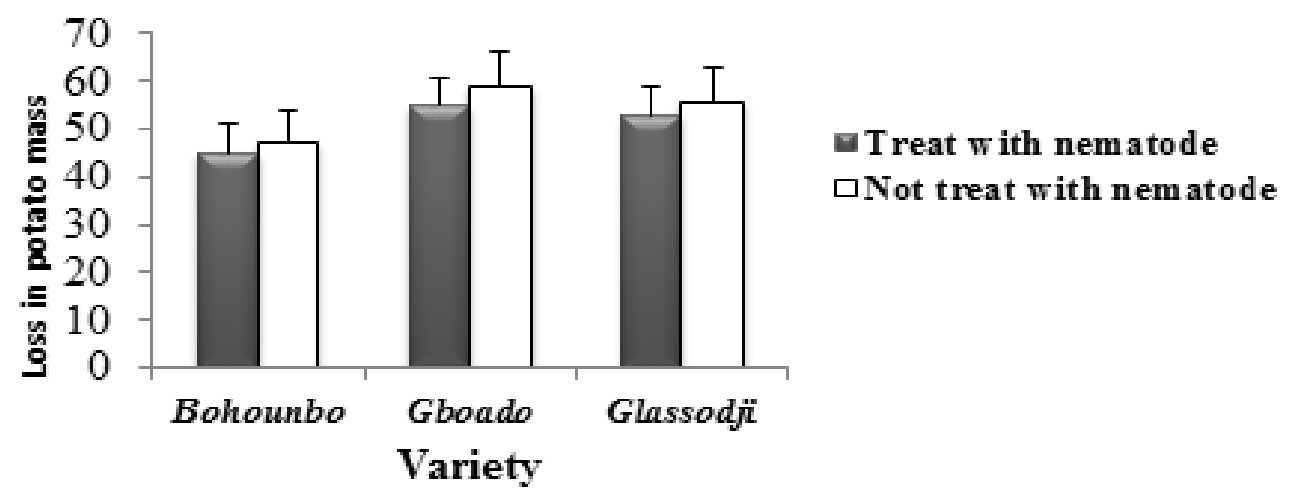

Figure 3: Average weight loss $( \pm \mathrm{SE})$ slices of roots damaged by $C$. puncticollis in laboratory conditions. 


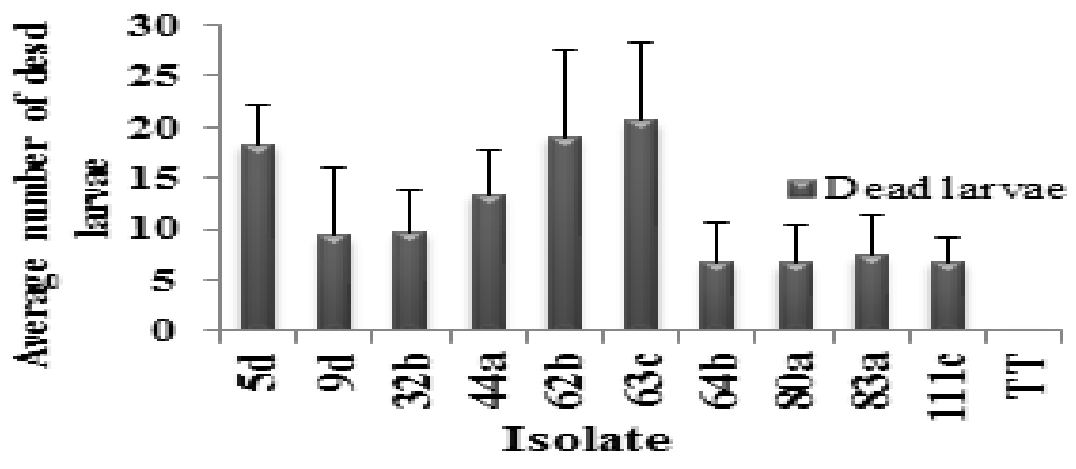

Figure 4: Average number of dead larvae for Bohounbo variety.

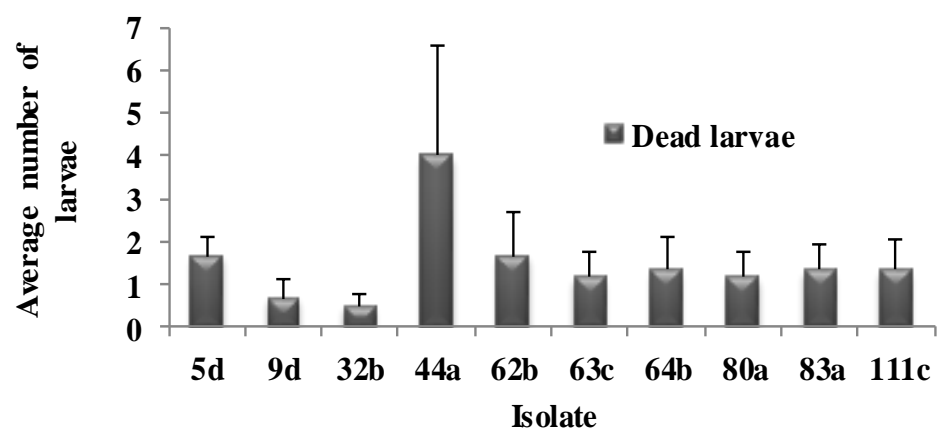

Figure 5: Average number of dead larvae for Gboado variety.

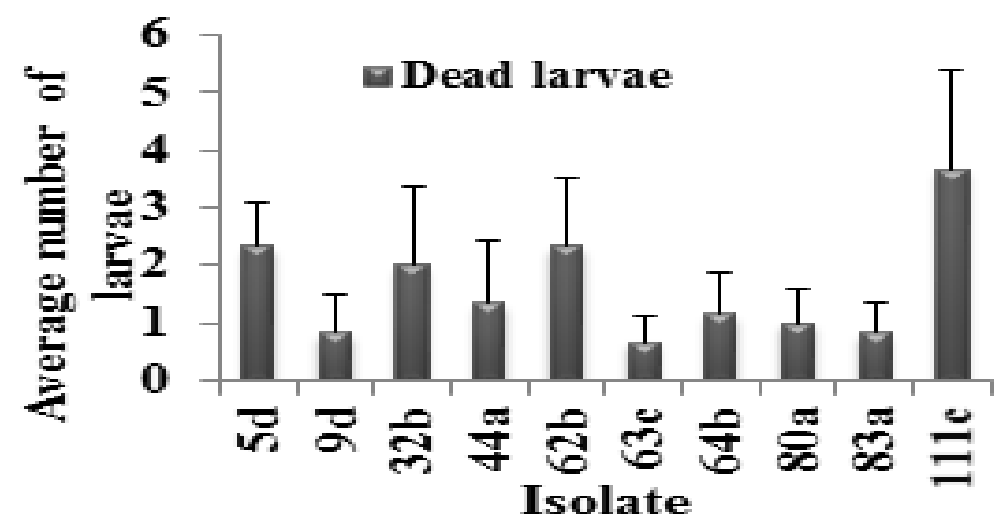

Figure 6: Average number of dead larvae for Glassodji variety. 


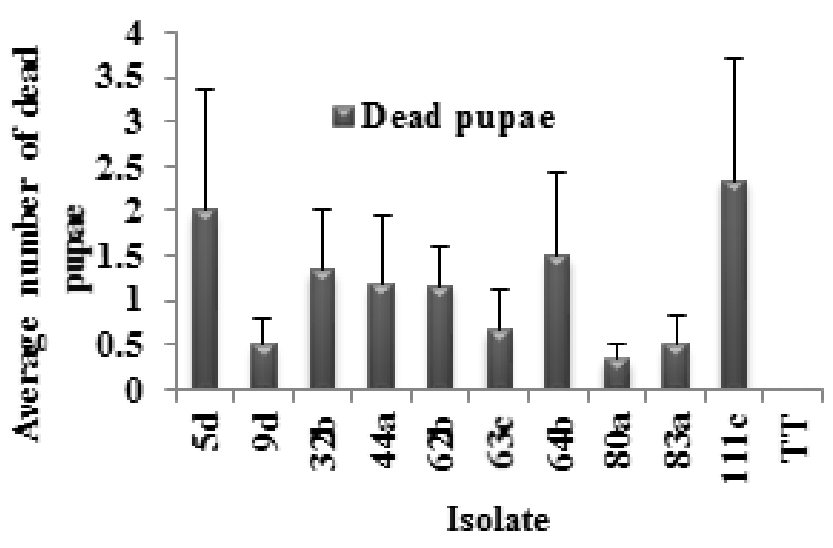

Figure 7: Average number of dead pupae for Bohounbo variety.

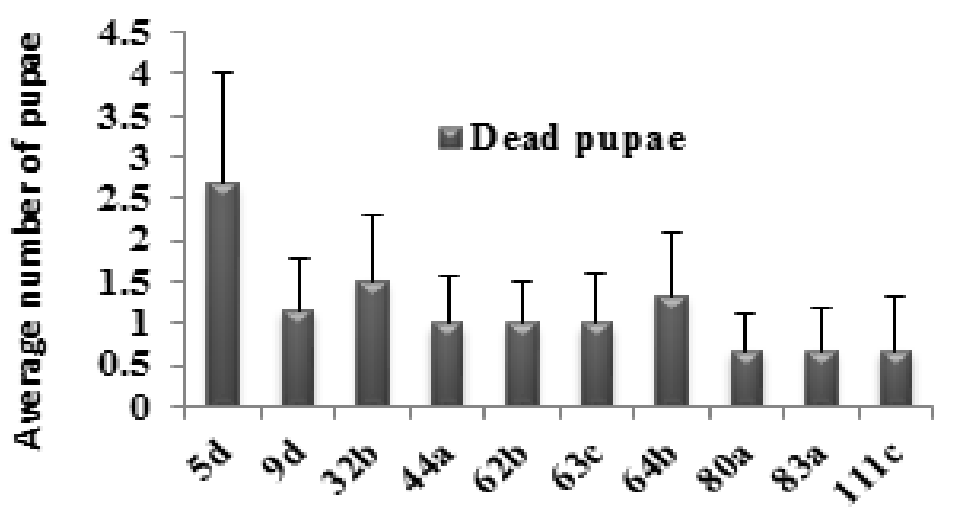

Isolate

Figure 8: Average number of dead pupae for Gboado variety.

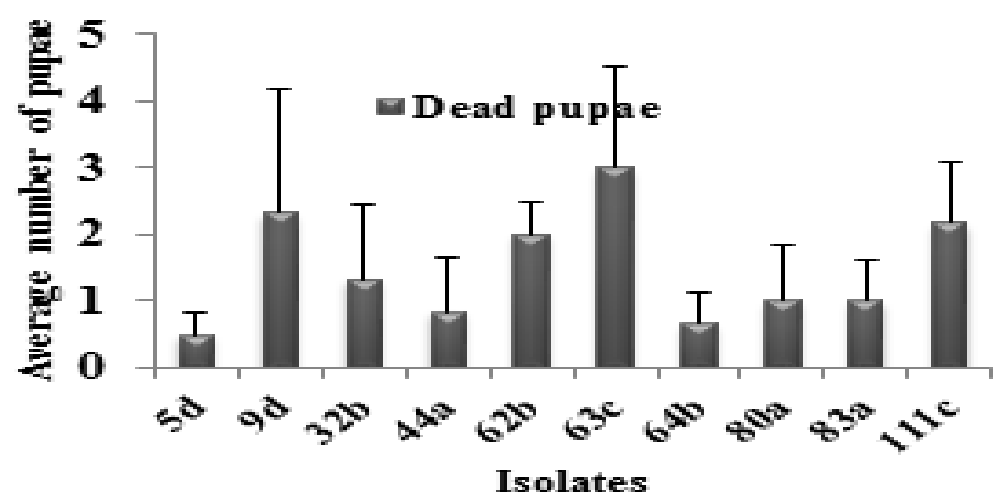

Figure 9: Average number of dead pupae for Glassodji variety. 


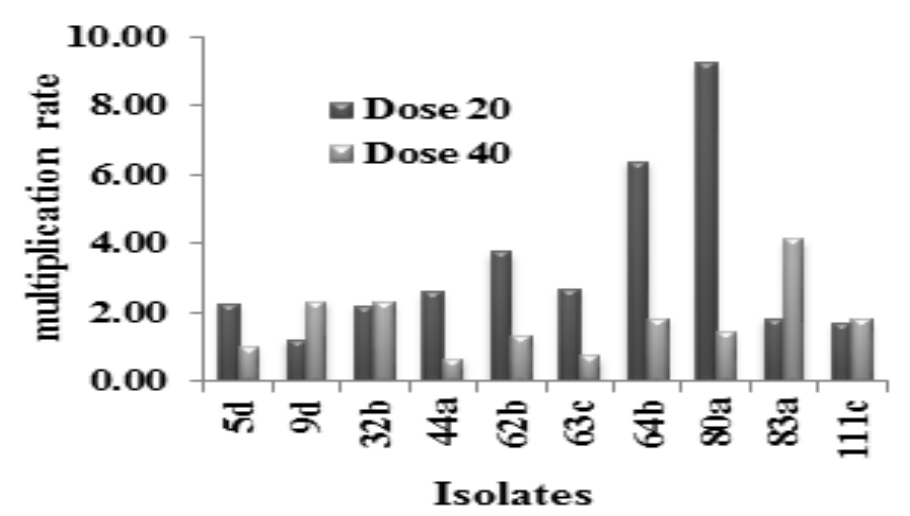

Figure 10: Average rate of multiplication of nematodes.

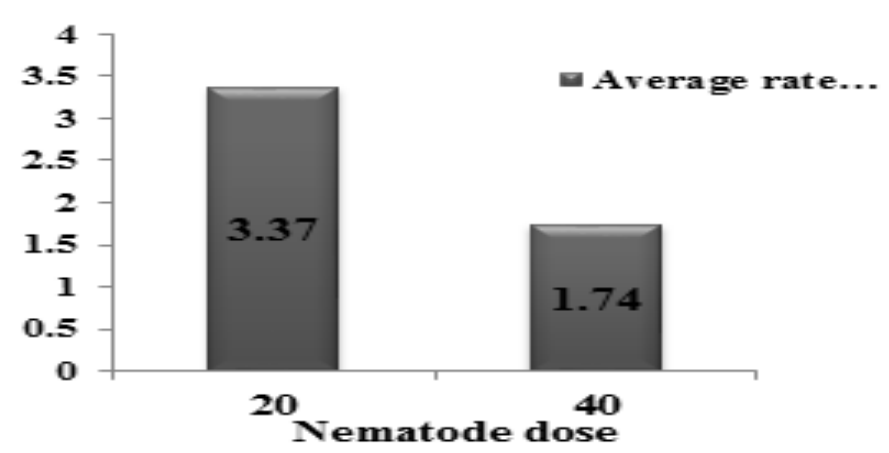

Figure 11: Average rate of reproduction of the nematodes by density.

Table 2: Weight loss sweet potato slices (\%) subject or not subject to infestation Cylas puncticollis.

\begin{tabular}{llll}
\hline Treatment & Bohounbo & Gboado & Glassodji \\
\hline TT & $\mathbf{4 7 , 0 0 A}$ & $\mathbf{5 8 , 8 5 A}$ & $\mathbf{5 5 , 5 0 A}$ \\
5d & 47,30 & 52,55 & 49,30 \\
9d & 44,80 & 55,00 & 49,10 \\
32b & 41,45 & 53,60 & 54,45 \\
44a & 45,05 & 52,65 & 52,55 \\
62b & 48,50 & 60,75 & 55,35 \\
63c & 44,70 & 60,65 & 55,70 \\
64b & 41,95 & 55,15 & 55,90 \\
80a & 42,60 & 50,15 & 52,90 \\
83a & 49,05 & 54,30 & 54,30 \\
111c & 44,90 & 53,50 & 51,70 \\
Average treated & $\mathbf{4 5 , 0 3 B}$ & $\mathbf{5 4 , 8 3 B}$ & $\mathbf{5 3 , 1 3 B}$ \\
\hline * Mean value with the same letter (A or B) in the same column are not significantly different.
\end{tabular}


Table 3: Average numbers of dead larvae collected during recounts with two doses of insect pathogenic nematodes.

\begin{tabular}{cllllll} 
& \multicolumn{4}{l}{ 20 entomopathogenic Nematodes } & \multicolumn{3}{l}{ 40 entomopathogenic Nematodes } \\
\cline { 2 - 7 } Treatments & Bohounbo & Gboado & Glassodji & \multicolumn{2}{l}{ Bohounbo } & \multicolumn{2}{l}{ Gboado } & Glassodji \\
\hline 5d & $17,33 \pm 3,71 \mathrm{ab}$ & $0 \pm 0 \mathrm{~b}$ & $4,33 \pm 1,20 \mathrm{a}$ & $19,33 \pm 3,71 \mathrm{a}$ & $3,33 \pm 0,88 \mathrm{a}$ & $0,33 \pm 0,33 \mathrm{~b}$ \\
9d & $9,00 \pm 8,50 \mathrm{abc}$ & $0 \pm 0 \mathrm{~b}$ & $0,66 \pm 0,33 \mathrm{~b}$ & $9,66 \pm 4,91 \mathrm{ab}$ & $1,33 \pm 0,88 \mathrm{a}$ & $1 \pm 1 \mathrm{~b}$ \\
$\mathbf{3 2 b}$ & $8,00 \pm 3,60 \mathrm{abc}$ & $0 \pm 0 \mathrm{~b}$ & $3,00 \pm 1,73 \mathrm{ab}$ & $11,33 \pm 4,70 \mathrm{ab}$ & $1 \pm 0,57 \mathrm{a}$ & $1 \pm 1 \mathrm{~b}$ \\
$\mathbf{4 4 a}$ & $11,66 \pm 4,33 \mathrm{abc}$ & $4,00 \pm 2,51 \mathrm{a}$ & $2,66 \pm 2,18 \mathrm{ab}$ & $15 \pm 4,35 \mathrm{ab}$ & $4 \pm 2,64 \mathrm{a}$ & $0 \pm 0 \mathrm{~b}$ \\
$\mathbf{6 2 b}$ & $20,66 \pm 6,11 \mathrm{a}$ & $1,66 \pm 0,88 \mathrm{ab}$ & $3,00 \pm 1,52 \mathrm{ab}$ & $17,33 \pm 11,09 \mathrm{ab}$ & $1,66 \pm 1,20 \mathrm{a}$ & $1,66 \pm 0,88 \mathrm{~b}$ \\
$\mathbf{6 3 c}$ & $21,00 \pm 5,77 \mathrm{a}$ & $1,33 \pm 1,33 \mathrm{ab}$ & $1,00 \pm 0,57 \mathrm{ab}$ & $20,33 \pm 9,49 \mathrm{a}$ & $1 \pm 0,57 \mathrm{a}$ & $0,33 \pm 0,33 \mathrm{~b}$ \\
$\mathbf{6 4 b}$ & $13,33 \pm 7,51 \mathrm{abc}$ & $0,33 \pm 0,33 \mathrm{~b}$ & $2,33 \pm 1,45 \mathrm{ab}$ & $0,33 \pm 0,33 \mathrm{~b}$ & $2,33 \pm 1,20 \mathrm{a}$ & $0 \pm 0 \mathrm{~b}$ \\
$\mathbf{8 0 a}$ & $1,00 \pm 0,57 \mathrm{c}$ & $1,66 \pm 0,88 \mathrm{ab}$ & $1,00 \pm 0,57 \mathrm{ab}$ & $12,33 \pm 6,69 \mathrm{ab}$ & $0,66 \pm 0,33 \mathrm{a}$ & $1 \pm 0,57 \mathrm{~b}$ \\
$\mathbf{8 3 a}$ & $9,33 \pm 6,17 \mathrm{abc}$ & $2,33 \pm 0,88 \mathrm{ab}$ & $1,33 \pm 0,66 \mathrm{ab}$ & $5,33 \pm 2,02 \mathrm{ab}$ & $0,33 \pm 0,33 \mathrm{a}$ & $0,33 \pm 0,33 \mathrm{~b}$ \\
$\mathbf{1 1 1}$ & $4,00 \pm 3,05 \mathrm{bc}$ & $0 \pm 0 \mathrm{~b}$ & $2,00 \pm 0,57 \mathrm{ab}$ & $9,66 \pm 1,45 \mathrm{ab}$ & $2,66 \pm 1,45 \mathrm{a}$ & $5,33 \pm 2,90 \mathrm{a}$ \\
\hline
\end{tabular}

Table 4: Average number of dead pupae collected during recounts with two doses of insects pathogenic nematodes.

\begin{tabular}{lllllll}
\hline & \multicolumn{2}{l}{ 20 nematodes } & \multicolumn{3}{c}{ 40 nematodes } \\
\cline { 2 - 7 } Treatments & Bohounbo & Gboado & Glassodji & Bohounbo & Gboado & Glassodji \\
\hline 5d & $1,67 \pm 0,88 \mathrm{ab}$ & $1,67 \pm 0,33 \mathrm{ab}$ & $0,67 \pm 0,33 \mathrm{a}$ & $2,33 \pm 1,85 \mathrm{a}$ & $3,67 \pm 2,33 \mathrm{a}$ & $0,33 \pm 0,33 \mathrm{a}$ \\
9d & $1 \pm 0,58 \mathrm{ab}$ & $1,33 \pm 0,67 \mathrm{abc}$ & $2,67 \pm 2,67 \mathrm{a}$ & $0 \pm 0 \mathrm{a}$ & $1 \pm 0,57 \mathrm{ab}$ & $2 \pm 1 \mathrm{a}$ \\
32b & $0,67 \pm 0,33 \mathrm{ab}$ & $2 \pm 1 \mathrm{a}$ & $1,33 \pm 0,89 \mathrm{a}$ & $2 \pm 1 \mathrm{a}$ & $1 \pm 0,58 \mathrm{ab}$ & $1,33 \pm 1,33 \mathrm{a}$ \\
$\mathbf{4 4 a}$ & $0,67 \pm 0,33 \mathrm{ab}$ & $1 \pm 0,57 \mathrm{abc}$ & $0,33 \pm 0,33 \mathrm{a}$ & $1,67 \pm 1,2 \mathrm{a}$ & $1 \pm 0,57 \mathrm{ab}$ & $1,33 \pm 1,33 \mathrm{a}$ \\
$\mathbf{6 2 b}$ & $0 \pm 0 \mathrm{~b}$ & $0,33 \pm 0,33 \mathrm{bc}$ & $2,33 \pm 0,67 \mathrm{a}$ & $2,33 \pm 0,88 \mathrm{a}$ & $1,67 \pm 0,67 \mathrm{ab}$ & $1,67 \pm 0,33 \mathrm{a}$ \\
$\mathbf{6 3 c}$ & $1 \pm 0,58 \mathrm{ab}$ & $0,67 \pm 0,33 \mathrm{abc}$ & $3 \pm 1 \mathrm{a}$ & $0,33 \pm 0,33 \mathrm{a}$ & $1,33 \pm 0,88 \mathrm{ab}$ & $3 \pm 2,08 \mathrm{a}$ \\
$\mathbf{6 4 b}$ & $2,331,2 \mathrm{a}$ & $0,33 \pm 0,33 \mathrm{bc}$ & $0,33 \pm 0,33 \mathrm{a}$ & $0,67 \pm 0,67 \mathrm{a}$ & $2,33 \pm 1,2 \mathrm{ab}$ & $1 \pm 0,58 \mathrm{a}$ \\
$\mathbf{8 0 a}$ & $0,67 \pm 0,33 \mathrm{ab}$ & $1 \pm 0,58 \mathrm{abc}$ & $0,67 \pm 0,33 \mathrm{a}$ & $0 \pm 0 \mathrm{a}$ & $0,33 \pm 0,33 \mathrm{~b}$ & $1,33 \pm 1,33 \mathrm{a}$ \\
$\mathbf{8 3 a}$ & $0,33 \pm 0,33 \mathrm{ab}$ & $0,67 \pm 0,67 \mathrm{abc}$ & $0,67 \pm 0,33 \mathrm{a}$ & $0,67 \pm 0,33 \mathrm{a}$ & $0,67 \pm 0,33 \mathrm{ab}$ & $1,33 \pm 0,89 \mathrm{a}$ \\
$\mathbf{1 1 1 c}$ & $1,67 \pm 1,2 \mathrm{ab}$ & $0 \pm 0 \mathrm{c}$ & $1,67 \pm 1,2 \mathrm{a}$ & $3 \pm 1,53 \mathrm{a}$ & $1,33 \pm 1,33 \mathrm{ab}$ & $2,67 \pm 0,67 \mathrm{a}$ \\
\hline
\end{tabular}

* Mean value with the same letter in the same column are not significantly different.

Table 5: Average number of dead adult insects.

\begin{tabular}{lllllll}
\hline & \multicolumn{3}{l}{ 20 nematodes } & \multicolumn{3}{c}{ 40 nematodes } \\
\cline { 2 - 7 } Treatments & Bohounbo & Gboado & Glassodji & Bohounbo & Gboado & Glassodji \\
\hline 5d & $3,67 \pm 0,88 \mathrm{a}$ & $2,67 \pm 2,18 \mathrm{a}$ & $1,33 \pm 0,33 \mathrm{a}$ & $1,67 \pm 0,67 \mathrm{c}$ & $1,65 \pm 1,73 \mathrm{a}$ & $3,67 \pm 0,88 \mathrm{a}$ \\
9d & $2,67 \pm 0,33 \mathrm{a}$ & $3,67 \pm 3,18 \mathrm{a}$ & $2 \pm 2,33 \mathrm{a}$ & $2,33 \pm 0,67 \mathrm{bc}$ & $1 \pm 0,58 \mathrm{a}$ & $2,67 \pm 0,33 \mathrm{a}$ \\
32b & $4,33 \pm 0,88 \mathrm{a}$ & $2,67 \pm 2,33 \mathrm{a}$ & $1 \pm 0 \mathrm{a}$ & $4,33 \pm 0,88 \mathrm{ab}$ & $3,33 \pm 1,76 \mathrm{a}$ & $3 \pm 1 \mathrm{a}$ \\
$\mathbf{4 4 a}$ & $3,67 \pm 0,33 \mathrm{a}$ & $2,67 \pm 0,33 \mathrm{a}$ & $1,67 \pm 1,33 \mathrm{a}$ & $2 \pm 1 \mathrm{c}$ & $6 \pm 2,08 \mathrm{a}$ & $2,67 \pm 1,76 \mathrm{a}$ \\
$\mathbf{6 2 b}$ & $4,33 \pm 2,96 \mathrm{a}$ & $1,67 \pm 2,73 \mathrm{a}$ & $2 \pm 2,33 \mathrm{a}$ & $4,33 \pm 1,33 \mathrm{ab}$ & $4 \pm 1 \mathrm{ab}$ & $2 \pm 0,58 \mathrm{a}$ \\
$\mathbf{6 3 c}$ & $3,33 \pm 0,88 \mathrm{a}$ & $3,67 \pm 3,17 \mathrm{a}$ & $1 \pm 0 \mathrm{a}$ & $3 \pm 0,58 \mathrm{bc}$ & $1,9 \pm 0,57 \mathrm{a}$ & $2,67 \pm 0,88 \mathrm{a}$ \\
$\mathbf{6 4 b}$ & $2,33 \pm 0,67 \mathrm{a}$ & $2,33 \pm 0,33 \mathrm{a}$ & $1,05 \pm 1,67 \mathrm{a}$ & $2,67 \pm 1,33 \mathrm{bc}$ & $2,02 \pm 2,33 \mathrm{a}$ & $2 \pm 1 \mathrm{a}$ \\
$\mathbf{8 0 a}$ & $2,67 \pm 0,33 \mathrm{a}$ & $2,33 \pm 0,67 \mathrm{a}$ & $2,03 \pm 0,67 \mathrm{a}$ & $3,67 \pm 0,88 \mathrm{abc}$ & $3,33 \pm 0,67 \mathrm{a}$ & $1,67 \pm 0,67 \mathrm{a}$ \\
$\mathbf{8 3 a}$ & $3 \pm 0,58 \mathrm{a}$ & $3,67 \pm 2,4 \mathrm{a}$ & $1,04 \pm 1,45 \mathrm{a}$ & $2,33 \pm 0,88 \mathrm{bc}$ & $3,33 \pm 0,33 \mathrm{a}$ & $4,33 \pm 1,45 \mathrm{a}$ \\
$\mathbf{1 1 1 c}$ & $4,33 \pm 0,33 \mathrm{a}$ & $2,33 \pm 0,88 \mathrm{a}$ & $1,78 \pm 1 \mathrm{a}$ & $3,67 \pm 0,67 \mathrm{abc}$ & $5,33 \pm 1,45 \mathrm{a}$ & $5,33 \pm 2,18 \mathrm{a}$ \\
\hline
\end{tabular}

* Mean value with the same letter in the same column are not significantly different. 


\section{DISCUSSION}

The results showed no significant difference between the weight obtained from the tubers inoculated with insects and treated with nematodes and the weight of insectinoculated control roots with no nematode treatment. These results are consistent with those obtained by Kenyan (Stathers et al., 2003) indicating that the weevils feed and generally affect the quality of infested roots, rendering them unmarketable. This is because the weevil diet induces the production of terpenoids by roots, making them unpleasant to taste, and therefore constitute losses not only for trading but also for consumption.

Any approach to control pests in a short period is the best. Thus, from the analysis of the results on the average number of dead larvae, it appears that all isolates used were effective and significantly reduced the emergence of adult weevils in the roots. These observations are more plausible on the Bohounbo variety than the other two varieties. The fact that different stages of sweet potato weevil occur at the same time, promotes the effectiveness of entomopathogenic nematodes to control their abundance, because of attraction and mobility of entomopathogenic nematodes to the host insect. The weevil attacks result in long winding galleries left by the larvae and filled with their faeces, that reduces the volume of roots and makes them unfit for human consumption.

The results also show that the larval stage was considered the most sensitive to the actions of nematodes. This corroborates findings by Ekanayake et al. (2001) who stated that the larvae have a soft cuticle and their stage lasts two to three weeks, giving enough time to nematodes to act. All this explains the high rate of larvae mortality. The Heterorhabditis are more effective on $C$. puncticollis larvae. Otherwise, isolates $62 \mathrm{~b}$ $63 \mathrm{c}$ and $5 \mathrm{~d}$ were more effective than others. Ekanayake et al. (2001) also reported high larval mortality of Cylas spp due to heterorhabditid and steinernematid. The results of the present study confirm laboratory experiments conducted in Kenya where the sweet potato weevil larvae are more susceptible to insect pathogenic nematodes (Nderitu et al., 2009).

Contrary to the action of the nematodes on larvae, the results showed that the nematode isolates used did not give the same effect on pupae. In fact, the pupation stage of Cylas puncticollis is very short and occurs within one week. This short period of pupation could not permit the entomopathogenic nematodes to infect the pupae properly and killed them. Also, the cuticle of the pupae is harder than the cuticle of larvae and did not facilitate the easy penetration of entomopathogenic nematodes (Ekanayake et al., 2001).

Unlike the infestation of young stages

of C. puncticollis, the penetration of nematodes in adult weevils is threatened by the hard outer cuticle, leading to a much lower adult mortality in our experiment. The low effectiveness of entomopathogenic nematodes on other adult weevils (Cosmopolites sordidus) has been reported (Chabrier and Mauléon, 2003; McGraw and Koppenhöfer, 2008). As our results, those authors working on biological control of Cosmopolites sordidus of bananas found that entomopathogenic nematodes are more effective on larval stages than adult stages. The same results have been reported by McGraw and Koppenhöfer (2008). However, the effectiveness of nematodes on larvae is more important in reducing weevil damage, since the next generation of weevils is greatly diminished.

In the system of sweet potato weevil, the ability of infectious juveniles to multiply is important for the persistence and global reuse of these entomopathogenic nematodes. Our study proved that all nematode isolates were able to multiply and emerge from dead larvae. However, there are some differences between the rates of multiplication of the nematode species tested. These differences are also reported by previous experiments on the sweet potato weevil (Capinera, 2012, Nderitu et al., 2009). The high percentage of larval mortality caused by Heterorhabditis 
nematodes can be attributed in part to their ability to multiply and produce more offspring in the weevil larvae (Nderitu et al., 2009). Despite the differences found between different isolates of nematodes, some are distinguished by their high multiplication rates. The isolates $80 \mathrm{a}, 64 \mathrm{~b}$ and $62 \mathrm{~b}$ presented the highest average rate of multiplication with 9, 7 and 4 times respectively.

\section{Conclusion}

The study initiated by the application of entomopathogenic nematodes to control Cylas puncticollis contributed to a better understanding of the need for biological control, which today is the plant protection method, the more recommended in the respect of the environment. After this study, we reached the main results which showed the following conclusions:

Cylas puncticollis would cause up to $100 \%$ loss in quality of sweet potato; all nematode isolates were effective against Cylas puncticollis; the larval stage of the insect is the most sensitive to the action of entomopathogenic nematodes; the isolates $63 \mathrm{c}, 62 \mathrm{~b}$ and $5 \mathrm{~d}$ were more effective than others. Therefore, they can be used for field trials.

\section{COMPETING INTERESTS}

The authors declare that they have no competing interests.

\section{AUTHORS' CONTRIBUTIONS}

AAF, HB and AT designed the experiments. AT performed the experiments. AAF and $\mathrm{HB}$ analysed the data. AAT wrote the manuscript. $\mathrm{AAF}$ and $\mathrm{HB}$ revised the manuscript.

\section{REFERENCES}

Ahmed M, Akter S, Eun J. 2010. Peeling, drying temperatures and sulphitetreatment affect physicochemical properties and nutritional quality of sweet potato flour. Food Chemistry, 121: 112-118.
Andrade M, Barker I, Cole D, Dapaah H, Elliott H, Fuentes S, Gruneberg W, Kapinga R, Kroschel J, Labarta R, Lemanga B, Loechel C, Low J, Mwanga R, Ortiz O, Oswald A, Thiele G. 2009. Unleashing the Potential of Sweet potato in Sub Saharan Africa: Current Challenges and Way forward. International Potato Center (CIP), Lima, Peru. Working Paper 1:197.

Azerad R. 2000. Regio- and stereoselective microbial hydroxylation of terpenoid compounds. In: Patel, R.N. (Eds.), Stereoselective Biocatalysis. Marcel Dekker, New York, pp. 153-180.

Capinera J. 2012. Sweetpotato Weevil, Cylas formicarius (Fabricius) (Insecta: Coleoptera: Brentidae (=Curculionidae)). University of Florida. Gainesville. 3p.

Chabrier C, Mauléon H. 2003. Use of entomopathogenic nematodes for banana black weevil control. In : Congresso Brasileiro de Nematologia, Petrolina, Brasil, 30 junho - 4 julho, 2003. s.l. : s.n., 1 p. Congresso Brasileiro de Nematologia. 24, Petrolina, Brésil, 30 June 2003/4 July 2003.

CIP (International Potato Center). 2007. Sweet Potato Research. CIP, Mexico. www.google.cgiar.

CIP (International Potato Center). 2008. Sweet potato Research. CIP, Mexico. www.google.cgiar.

Crinnion WJ. 2009. Chlorinated pesticides: threats to health and importance of detection. Altern Med Rev., 14(4):347359. www.intechopen.com

Dossou-Aminon I, Loko LY, Adjatin A, Dansi A, Elangovan M, Chaudhary P, Vodouhe R, Sanni A. 2014. Diversity, genetic erosion and farmers' preference of sorghum varieties [Sorghum bicolor (L.) Moench] in North-Eastern Benin. Int. J. Curr. Microbiol. Appl Sci., 3(10): 531552. http://www.ijcmas.com

Dufumier M. 2005. Créativité paysanne dans le tiers monde. Ecologie \& politique, $\mathbf{3 1}$ 
(2) :

95-108.

DOI : https://doi.org/10.3917/ecopo.031.0095

Ebregt E, Struik PC, Abidin PE, Odongo B. 2004. Farmers' Information on Sweet potato Production and Millipede Infestation in North-Eastern Uganda. II. Pest Incidence and Indigenous Control Strategies. NJAS-Wageningen. Journal of Life Science, 52: 69-84. DOI: https://doi.org/10.1016/S15735214(04)80030-7

Ebregt E, Struik PC, Odongo B, Abidin PE. 2005. Pest Damage in Sweet potato, Groundnut and Maize in North-Eastern Uganda with Special Reference Damage by Millipedes (Diplopoda). NJASWageningen. Journal of Life Sciences 53: 49-69.

DOI:

https://doi.org/10.1016/S15735214(05)80010-7

Ebregt E, Struik PC, Odongo B, Abidin PE. 2007. Field Observations on Piecemeal and One - Time Harvesting of Sweet potato in North- Eastern Uganda with Special Reference to Damage by Sweet potato Weevil (Cylas spp). NJAS Wageningen. Journal of Life Sciences, 55: 75- 92. DOI: 10.1016/S15735214(07)80005-4

Echodu R, Edema H, Wokorach G, Zawedde C. 2018. Farmers' practices and their knowledge of biotic constraints to sweet potato production in East Africa. Physiological and Molecular Plant Pathology, 105: 3-16. DOI: 10.1016/j.pmpp.2018.07.004

Ekanayake HMRK, Abeysinghe AMCP, Toida Y. 2001. Potential of entomopathogenic nematodes as biocontrol agents of sweet potato weevil, Cylas formicarius (FABRICIUS) (Coleoptera: Brenthidae). Journal of Nematology, 31: 19-25.

FAOSTAT. 2008.

http://faostat.fao.org/site/567/default.asp x\#ancor [visité le 17/06/14].
Glato K, Aidam A, Odah K, Tozo K, AttohMensah ML, Etse KD. 2014. Régénération in vitro par organogenèse directe de pousses à partir de boutures de trois cultivars de patate douce (Ipomoea batatas) originaire du Togo. European Scientific Journal, 10(27): 1857 - 7881.

Hashim NA, Zulkifli NA, Saad K, Basari N. 2017. The Infestation of Cylas formicarius (FABRICIUS) (COLEOPTERA: BRENTIDAE) and its effect on post-harvest quality of storage sweet potatoes. Malaysian Applied Biology, 46(3): 185-193.

Houékpétodji ZNAD. 2018. Evaluation de la susceptibilité de quelques accessions de patate douce à Cylas punticollis Boheman (charançon de la patate douce) en conditions de laboratoire. MémoireRecherche pour l'obtention du Diplôme de Licence Professionnelle. Université de Parakou, Bénin, 53p.

IITA. 1988. Annual Report and Research Highlights - IITA. IITA, Ibadan, 50 p.

Maling'a JNB. 2000. Studies on Sweet potato Weevil Cylas spp With Special Emphasis on Effects of Cultural Practices on Weevil Damage and Yields of Sweet potato (Ipomoea batatas Lam). MSc Thesis, Egerton University.

McGraw BA, Koppenhofer AM. 2008. Evaluation of two endemic and five commercial entomopathogenic nematode species (Rhabditida: Heterorhabditidae and Steinernematidae) against annual bluegrass weevil (Coleoptera: Curculionidae) larvae and adults. Biological Control, 46: 467-475. DOI: 10.1016/j.biocontrol.2008.03.012

Nderitu J, Sila M, Nyamasyo G, Kasina M. 2009. Effectiveness of Entomopathogenic Nematodes against Sweet Potato Weevil (Cylas puncticollis Boheman (Coleoptera: Apionidae)] Under Semi-Field Conditions in Kenya. Journal of Entomology, 6(3): 145-154. DOI: 10.3923/je.2009.145.154 
Pathleen T, Janet L. 2015. Cassava and sweet potato: suitability of popular Caribbean varieties for value added product development / CARDI, IICA -- Port of Spain. IICA, $122 \mathrm{p}$.

Sivparsad BJ, Gubba A. 2012. Development of an efficient plant regeneration protocol for sweet potato (Ipomoea batatas L.) cv. Blesbok. African Journal of Biotechnology, 11(84): 14982-14987. DOI: $10.5897 / A J B 12.2249$ ISSN 1684 5315

Stathers TE, Rees D, Nyango A, Kiozya H, Mbilinyi L, Jeremiah S, Kabi S, Smit N. 2003. Sweet potato Infestation by Cylas spp. In East Africa: II. Investigating the Role of Root Characteristics. International Journal of Pest Management, 49(2):141-146. DOI: https://doi.org/10.1080/09670870210000 43094
Tomlins K, Owori C, Bechoff A, Menya G, Westby A. 2012. Relationship among the carotenoid content, dry matter content and sensory attributes of sweet potato. Food Chemistry, 131(1): 14-21. DOI: 10.1016/j.foodchem.2011.07.072

Ukom AN, Ojimelukwe PC, Okpara DA. 2009. Nutrient composition of select sweet potato [Ipomoea batatas (L. lam)] Varieties as influenced by different level of nitrogen fertilizer application. Pakistan Journal of Nutrition, 8(11) 1791-1795.

DOI: 10.3923/pjn.2009.1791.1795

Van Oirschot QEA, Rees D, Aked J. 2003. Sensory characteristics of five sweet potato cultivars and their changes during storage under tropical conditions. Food Quality and Preference, 14: 673-680. DOI: 10.1016/S0950-3293(02)00209-4 